\title{
Electrochemical and chemical routes to hydride loss from an iridium dihydride $\uparrow$
}

Cite this: Dalton Trans., 2016, 45 , 9766

Received 5th February 2016,

Accepted 4th March 2016

DOI: 10.1039/c6dt00522e

www.rsc.org/dalton

With a view towards replacing sacrificial hydrogen acceptors in alkane dehydrogenation catalysis, electrochemical methods for oxidative activation of a pincer-ligated iridium hydride intermediate were explored. A $1 \mathrm{H}^{+} / 2 \mathrm{e}^{-}$oxidation process was observed in THF solvent, with net hydride loss leading to a reactive cationic intermediate that can be trapped by chloride. Analogous reactivity was observed with the concerted hydride transfer reagent $\mathrm{Ph}_{3} \mathrm{C}^{+}$, connecting chemical and electrochemical hydride loss pathways.

Iridium complexes supported by tridentate ${ }^{\mathrm{R}_{4}} \mathrm{PCP}\left({ }^{\mathrm{R}_{4}} \mathrm{PCP}=\right.$ $\left.\kappa^{3}-\mathrm{C}_{6} \mathrm{H}_{3}-2,6-\left(\mathrm{CH}_{2} \mathrm{PR}_{2}\right)_{2}\right)$ pincer ligands are prolific dehydrogenation catalysts, enabling landmark transformations such as the dehydrogenation, ${ }^{1,2}$ metathesis, ${ }^{3}$ coupling ${ }^{4,5}$ and dehydroaromatization $^{6}$ of alkanes. ${ }^{7}$ Efficient dehydrogenation reactions require a sacrificial hydrogen acceptor, typically an olefin. The hydrogen acceptor alters the overall reaction thermodynamics and activates the iridium dihydride species. $^{7-9}$ In transfer dehydrogenation, catalyst activation occurs by insertion of the sacrificial olefin into one Ir-H bond, followed by $\mathrm{C}-\mathrm{H}$ bond-forming reductive elimination with the other Ir-H bond, generating a highly reactive $14 \mathrm{e}^{-}$intermediate capable of alkane $\mathrm{C}-\mathrm{H}$ bond activation (Scheme 1).

The requirement of an added stoichiometric reagent represents a significant limitation in dehydrogenation reactions. ${ }^{8,10}$ In considering new strategies to promote dehydrogenation reactions, we were drawn to electrochemical methods that could decouple the catalyst activating and hydrogen accepting steps. ${ }^{11,12}$ We envisioned electrochemical oxidation of $\left({ }^{R_{4}} \mathrm{PCP}\right) \operatorname{Ir}(\mathrm{H})_{2}$ at an anode, generating a catalytic intermediate while releasing $2 \mathrm{H}^{+} / 2 \mathrm{e}^{-}$(Scheme 1 ) that could be used to drive any range of reactions at the cathode.

${ }^{a}$ Department of Chemistry, University of North Carolina at Chapel Hill, Chapel Hill, NC 27599-3290, USA. E-mail: ajmm@email.unc.edu

${ }^{b}$ Department of Chemistry and Chemical Biology, Rutgers, The State University of New Jersey, New Brunswick, New Jersey 08903, USA

${ }^{c}$ Department of Chemistry, Indian Institute of Technology Guwahati,

Guwahati - 781039, Assam, India

$\dagger$ Electronic supplementary information (ESI) available: Experimental details, electrochemical data, and NMR spectra. See DOI: 10.1039/c6dt00522e

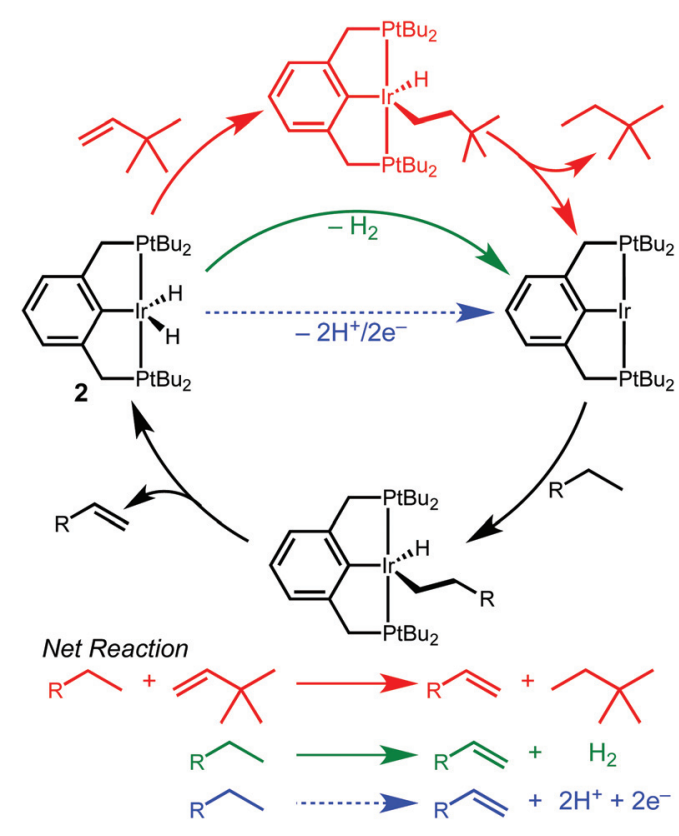

Scheme 1

Electrochemical dehydrogenation relies on (sometimes coupled) electron transfer and proton transfer steps, ${ }^{13,14}$ while chemical dehydrogenation often involves concerted hydride transfer. ${ }^{7,15,16}$ Recent reports have started to draw connections between chemical and electrochemical processes, however. For example, inspired by a report of $\left({ }^{\mathrm{R}_{4}} \mathrm{PCP}\right)$ Ir-catalyzed hydrogenation of $\mathrm{CO}_{2}$ to formate, ${ }^{17}$ Brookhart and Meyer developed an analogous electrochemical reduction of $\mathrm{CO}_{2}$ to formate catalyzed by $\left({ }^{t \mathrm{Bu}_{4}} \mathrm{POCOP}\right)$ Ir complexes $\left({ }^{t \mathrm{Bu}_{4}} \mathrm{POCOP}=\kappa^{3}-\mathrm{C}_{6} \mathrm{H}_{3}-2,6-\right.$ $\left.\left(\mathrm{OP}^{t} \mathrm{Bu}_{2}\right)_{2}\right){ }^{18-20} \mathrm{~A}$ striking oxidative example involves two different catalysts for the same alcohol oxidation reaction that operate by two different mechanisms, either a concerted $\mathrm{H}_{2}$ loss mechanism or an outer-sphere electron transfer mechanism in which a chemical oxidant (not an electrode) and a base facilitate $2 \mathrm{H}^{+} / 2 \mathrm{e}^{-}$loss. ${ }^{21}$ 
Studies of electrochemical reactions that parallel wellknown organometallic oxidations can help bridge the divide between chemical and electrochemical methods. This report focuses on the oxidation of a pincer-ligated iridium dihydride. Net loss of hydride $\left(\mathrm{H}^{+} / 2 \mathrm{e}^{-}\right)$is promoted by either electrochemical or chemical methods to produce an iridium monohydride species.

The dihydride complex was prepared according to previously reported procedures by dehydrohalogenation of $\left.{ }^{t \mathrm{Bu}_{4}} \mathrm{PCP}\right) \operatorname{Ir}(\mathrm{H})(\mathrm{Cl})(\mathbf{1})$ under an $\mathrm{H}_{2}$ atmosphere. ${ }^{1,22}$ This procedure affords a mixture of the five-coordinate dihydride $\left({ }^{t \mathrm{Bu}_{4}} \mathrm{PCP}\right) \operatorname{Ir}(\mathrm{H})_{2}(2)$ and $\left({ }^{t \mathrm{Bu}_{4}} \mathrm{PCP}\right) \operatorname{Ir}(\mathrm{H})_{4}(3) .{ }^{23}$ Samples could be stirred in pentane, filtered, and dried under vacuum to remove the dihydrogen ligand and provide pure $2 .+$

The oxidation of dihydride 2 was initially explored using cyclic voltammetry (CV). When a solution of 2 in argon-saturated THF containing $\left[\mathrm{Bu}_{4} \mathrm{~N}\right]\left[\mathrm{PF}_{6}\right]$ supporting electrolyte was assessed by a CV sweep to oxidative potentials, a single irreversible feature was observed at $-0.08 \mathrm{~V} v s . \mathrm{Cp}_{2} \mathrm{Fe}^{+/ 0}$ (Fig. 1). No return reduction process was apparent, even as the scan rate was increased to $1 \mathrm{~V} \mathrm{~s}^{-1}$.

An irreversible electrochemical oxidation is consistent with a rapid chemical reaction following electron transfer from 2 to the electrode. The dihydride $\mathbf{2}$ is more easily oxidized than the hydridochloride complex $\mathbf{1}$, which exhibited a quasi-reversible oxidation around $0.5 \mathrm{~V} v$ s. $\mathrm{Cp}_{2} \mathrm{Fe}^{+/ 0}$ in $\mathrm{CH}_{2} \mathrm{Cl}_{2}$ at fast scan rates in a prior study. ${ }^{24}$

To identify the product formed at positive potentials under argon, a controlled potential electrolysis experiment was carried out. A high-surface-area reticulated vitreous carbon working electrode was submersed in a THF solution of dihydride 2 and polarized to $0.2 \mathrm{~V}$ vs. $\mathrm{Cp}_{2} \mathrm{Fe}^{+/ 0}$. The flow of current diminished as a gradual color change from pale orange to pale yellow was observed. The oxidation passed $239 \mathrm{mC}$ of charge, corresponding to $1.9 \mathrm{e}^{-}$per $\mathrm{Ir}$, but an aliquot analyzed by ${ }^{31} \mathrm{P}\left\{{ }^{1} \mathrm{H}\right\}$ NMR spectroscopy revealed a mixture of species.

Considering the possibility that oxidation of 2 would produce a reactive cationic species, ${ }^{25}$ the oxidative electrochemistry was also carried out in the presence of a chloride ion source as a trapping agent. In the presence of $\mathrm{LiCl}$ (and

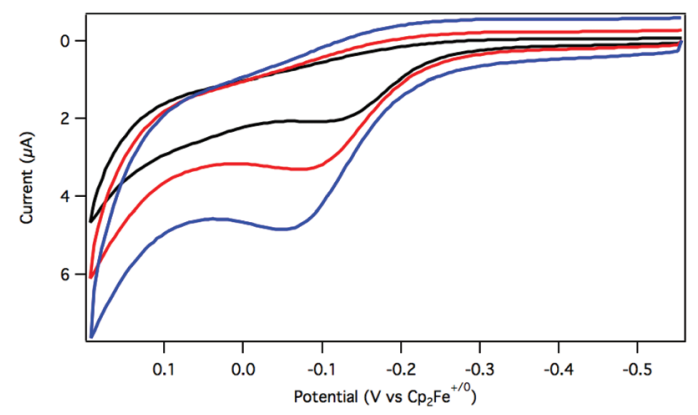

Fig. 1 Cyclic voltammetry of 2 at $25 \mathrm{mV} \mathrm{s}^{-1}$ (black), $100 \mathrm{mV} \mathrm{s}^{-1}$ (red), and $250 \mathrm{mV} \mathrm{s}^{-1}$ (blue) in THF solution with $\left.0.1 \mathrm{M}^{2} \mathrm{Bu}_{4} \mathrm{~N}\right]\left[\mathrm{PF}_{6}\right]$ electrolyte. Glassy carbon working electrode, platinum counter electrode, Ag wire pseudo-reference electrode, $298 \mathrm{~K}$.

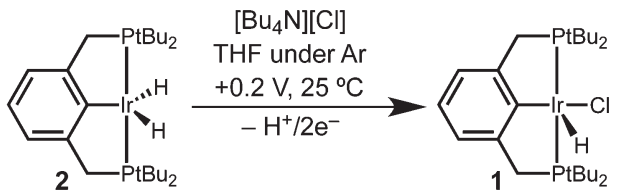

Scheme 2

with conditions otherwise similar to those described above), the $\mathrm{CV}$ response of $\mathbf{2}$ was essentially unchanged relative to chloride-free conditions, suggesting that chloride does not influence the initial oxidation process.

Controlled potential electrolysis of a THF solution containing 2 and excess $\mathrm{LiCl}$ or $\left[\mathrm{Bu}_{4} \mathrm{~N}\right][\mathrm{Cl}]$ was conducted at $0.2 \mathrm{~V}$ vs. $\mathrm{Cp}_{2} \mathrm{Fe}^{+/ 0}$ (Scheme 2). In the presence of chloride, the solution color changed from pale orange to a much brighter orange, and the $283 \mathrm{mC}$ of charge passed corresponds to a $2 \mathrm{e}^{-}$oxidation (2.3 $\mathrm{e}^{-}$per Ir). Analysis by ${ }^{31} \mathrm{P}\left\{{ }^{1} \mathrm{H}\right\}$ NMR spectroscopy now revealed a single phosphorous-containing species $(\delta 69)$. The product was isolated from the electrolyte by removal of the THF under vacuum and extraction with pentane. Full NMR spectroscopic analysis in THF- $d_{8}$ showed a triplet hydride resonance far upfield $(\delta-42.9)$ in the ${ }^{1} \mathrm{H}$ NMR spectrum that is diagnostic of $\left({ }^{t \mathrm{Bu}_{4}} \mathrm{PCP}\right) \operatorname{Ir}(\mathrm{H})(\mathrm{Cl})(\mathbf{1})$. All of the ${ }^{31} \mathrm{P}$ and ${ }^{1} \mathrm{H}$ NMR signals closely matched the previously reported values. ${ }^{22}$

The electrochemical conversion of dihydride 2 to hydridochloride 1 represents a net hydride abstraction via the loss of $2 \mathrm{e}^{-}$to the anode and loss of $\mathrm{H}^{+}$(to solution or perhaps to a surface site on the electrode), followed by chloride binding. This two-step electrochemical-chemical (EC) transformation is consistent with the irreversible $\mathrm{CV}$ response (prior studies of (pincer) $\operatorname{Ir}(\mathrm{H})(\mathrm{Cl})$ also implicated an EC mechanism, but did not identify a product). ${ }^{24}$ The stability of the product, hydridochloride 1, towards further oxidation at the potentials applied during electrolysis is critical to the success of the reaction. ${ }^{24}$

Analogous electrochemical hydride loss via a two-electron/ one-proton oxidative process has been reported for a series of Group 6 complexes of the type $\mathrm{CpM}(\mathrm{CO}){ }_{3} \mathrm{H}(\mathrm{M}=\mathrm{Cr}, \mathrm{M}, \mathrm{W}){ }^{26}$ which may involve a concerted proton-coupled electron transfer event in the tungsten case. ${ }^{27}$ In contrast, the $\mathrm{Rh}$ analogue $\left({ }^{t \mathrm{Bu}_{4}} \mathrm{PCP}\right) \mathrm{Rh}\left(\mathrm{H}_{2}\right)$, which is best described as a $\mathrm{Rh}(\mathrm{I})$ dihydrogen complex, ${ }^{28}$ does not undergo oxidative hydride loss: reversible $1 \mathrm{e}^{-}$oxidation is observed in $\mathrm{CH}_{2} \mathrm{Cl}_{2}$, and $\mathrm{H}_{2}$ loss is observed in coordinating solvents. $^{29}$

To further probe the hydride transfer reactivity, chemical methods that could effect an analogous hydride loss were explored. When dihydride 2 is allowed to react with the hydride abstractor $\left[\mathrm{Ph}_{3} \mathrm{C}\right]\left[\mathrm{B}\left(\mathrm{C}_{6} \mathrm{~F}_{5}\right)_{4}\right]$ in THF- $d_{8}$, the solution changes color from pale orange to pale yellow. NMR spectroscopic monitoring revealed a mixture of products analogous to those observed in the initial electrolysis.

Hydride abstraction was next attempted in the presence of a chloride source. Treatment of dihydride 2 with 1 equiv. $\left[\mathrm{Ph}_{3} \mathrm{C}\right]\left[\mathrm{B}\left(\mathrm{C}_{6} \mathrm{~F}_{5}\right)_{4}\right]$ and 5 equiv. $\left[\mathrm{Bu}_{4} \mathrm{~N}\right][\mathrm{Cl}]$ led to a color change from pale orange to a much brighter orange, coinciding with 


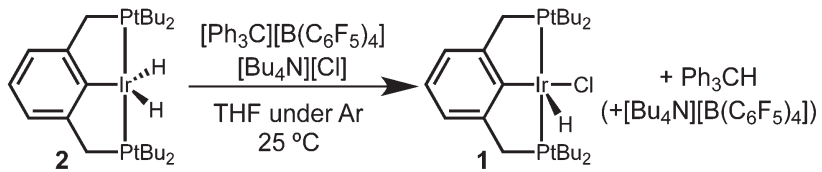

Scheme 3

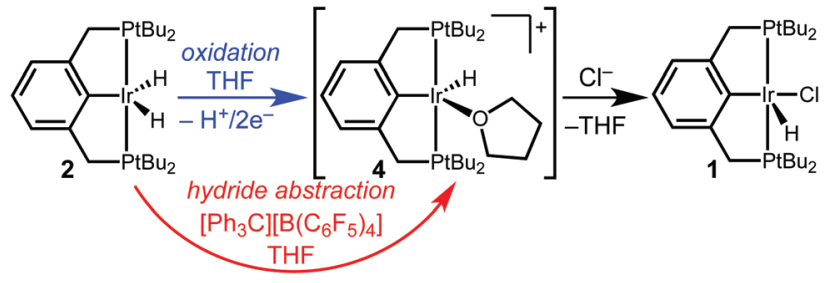

Scheme 4

the appearance of the characteristic signals of hydridochloride complex 1 by ${ }^{31} \mathrm{P}\left\{{ }^{1} \mathrm{H}\right\}$ and ${ }^{1} \mathrm{H}$ NMR spectroscopy (Scheme 3). Triphenylmethane is also observed by ${ }^{1} \mathrm{H}$ NMR spectroscopy, clearly identifying the fate of the hydride.

We suggest that the electrochemical and chemical hydride abstractions proceed via a shared intermediate, given the similar product distributions under various reaction conditions. As shown in Scheme 4, we hypothesize that oxidation of dihydride 2 occurs as a net $1 \mathrm{H}^{+} / 2 \mathrm{e}^{-}$process (via one of the pathways described above) to generate a reactive monohydride cation, $\left[\left({ }^{t \mathrm{Bu}_{4}} \mathrm{PCP}\right) \operatorname{Ir}(\mathrm{H})\right]^{+}$(4). Chemical hydride transfer from 2 to $\left[\mathrm{Ph}_{3} \mathrm{C}\right]\left[\mathrm{B}\left(\mathrm{C}_{6} \mathrm{~F}_{5}\right)_{4}\right]$ would also afford 4 . We are not aware of any prior reported isolation of cation 4. An analogous $\left[\left({ }^{t \mathrm{Bu}_{4}} \mathrm{POCOP}\right) \operatorname{Ir}(\mathrm{H})\right]^{+}$species, isolated as an acetone or dichloromethane adduct, is an active hydrosilylation catalyst. ${ }^{30,31}$

From this shared intermediate cation 4, trapping with chloride ion can generate the hydridochloride 1 . In the absence of chloride, we suspect that cation 4 decomposes through reactions with itself and/or the solvent, the details of which are currently under investigation. The observation of identical products under electrochemical and chemical reaction conditions suggests that future electrochemical oxidations (even in non-polar solvents) ${ }^{32-34}$ can be modeled after existing hydride abstraction reactions.

By implicating a key monohydride cation intermediate and building an analogy between well-defined organometallic hydride abstraction reactions and electrochemical oxidation processes, these joint chemical/electrochemical studies provide a foundation for future development of electrochemical dehydrogenation processes.

\section{Acknowledgements}

The authors acknowledge funding from NSF Center for Enabling New Technologies through Catalysis (CENTC), CHE-1205189. The Templeton group generously provided access to an argon-filled glovebox.

\section{Notes and references}

† Solutions containing hydrides 2 and 3 are stable under $\operatorname{Ar}$ or $\mathrm{H}_{2}$, but decompose under $\mathrm{N}_{2}$ or air to a mixture of products with distinct electrochemical responses. $^{35}$

1 M. Gupta, C. Hagen, R. J. Flesher, W. C. Kaska and C. M. Jensen, Chem. Commun., 1996, 2083-2084.

2 A. Kumar, T. Zhou, T. J. Emge, O. Mironov, R. J. Saxton, K. Krogh-Jespersen and A. S. Goldman, J. Am. Chem. Soc., 2015, 137, 9894-9911.

3 A. S. Goldman, A. H. Roy, Z. Huang, R. Ahuja, W. Schinski and M. Brookhart, Science, 2006, 312, 257-261.

4 D. C. Leitch, Y. C. Lam, J. A. Labinger and J. E. Bercaw, J. Am. Chem. Soc., 2013, 135, 10302-10305.

5 J. A. Labinger, D. C. Leitch, J. E. Bercaw, M. A. Deimund and M. E. Davis, Top. Catal., 2015, 58, 494-501.

6 R. Ahuja, B. Punji, M. Findlater, C. Supplee, W. Schinski, M. Brookhart and A. S. Goldman, Nat. Chem., 2011, 3, 167171.

7 J. Choi, A. H. Roy MacArthur, M. Brookhart and A. S. Goldman, Chem. Rev., 2011, 111, 1761-1779.

8 K. Krogh-Jespersen, M. Czerw, N. Summa, K. B. Renkema, P. D. Achord and A. S. Goldman, J. Am. Chem. Soc., 2002, 124, 11404-11416.

9 K. B. Renkema, Y. V. Kissin and A. S. Goldman, J. Am. Chem. Soc., 2003, 125, 7770-7771.

10 W. Xu, G. P. Rosini, K. Krogh-Jespersen, A. S. Goldman, M. Gupta, C. M. Jensen and W. C. Kaska, Chem. Commun., 1997, 2273-2274.

11 P. Driscoll, E. Deunf, L. Rubin, O. Luca, R. H. Crabtree, C. Chidsey, J. Arnold and J. Kerr, ECS Trans., 2011, 35, 3-17.

12 B. Rausch, M. D. Symes and L. Cronin, J. Am. Chem. Soc., 2013, 135, 13656-13659.

13 C. Costentin, M. Robert and J.-M. Savéant, Chem. Rev., 2010, 110, PR1-PR40.

14 D. R. Weinberg, C. J. Gagliardi, J. F. Hull, C. F. Murphy, C. A. Kent, B. C. Westlake, A. Paul, D. H. Ess, D. G. McCafferty and T. J. Meyer, Chem. Rev., 2012, 112, 4016-4093.

15 S. E. Clapham, A. Hadzovic and R. H. Morris, Coord. Chem. Rev., 2004, 248, 2201-2237.

16 C. R. Waidmann, A. J. M. Miller, C.-W. A. Ng, M. L. Scheuermann, T. R. Porter, T. A. Tronic and J. M. Mayer, Energy Environ. Sci., 2012, 5, 7771-7780.

17 R. Tanaka, M. Yamashita and K. Nozaki, J. Am. Chem. Soc., 2009, 131, 14168-14169.

18 P. Kang, C. Cheng, Z. Chen, C. K. Schauer, T. J. Meyer and M. Brookhart, J. Am. Chem. Soc., 2012, 134, 5500-5503.

19 P. Kang, T. J. Meyer and M. Brookhart, Chem. Sci., 2013, 4, 3497-3502.

20 P. Kang, S. Zhang, T. J. Meyer and M. Brookhart, Angew. Chem., Int. Ed., 2014, 53, 8709-8713.

21 P. J. Bonitatibus, S. Chakraborty, M. D. Doherty, O. Siclovan, W. D. Jones and G. L. Soloveichik, Proc. Natl. Acad. Sci. U. S. A., 2015, 112, 1687-1692. 
22 C. J. Moulton and B. L. Shaw, J. Chem. Soc., Dalton Trans., 1976, 1020-1024.

23 T. J. Hebden, K. I. Goldberg, D. M. Heinekey, X. Zhang, T. J. Emge, A. S. Goldman and K. Krogh-Jespersen, Inorg. Chem., 2010, 49, 1733-1742.

24 F. Novak, B. Speiser, H. A. Y. Mohammad and H. A. Mayer, Electrochim. Acta, 2004, 49, 3841-3853.

25 M. Gupta, W. C. Kaska and C. M. Jensen, Chem. Commun., 1997, 461-462.

26 O. B. Ryan, M. Tilset and V. D. Parker, J. Am. Chem. Soc., 1990, 112, 2618-2626.

27 M. Bourrez, R. Steinmetz, S. Ott, F. Gloaguen and L. Hammarström, Nat. Chem., 2015, 7, 140-145.

28 K. Huang, J. H. Han, C. B. Musgrave and E. Fujita, Organometallics, 2007, 26, 508-513.
29 M. D. Doherty, S. J. Konezny, V. S. Batista and G. L. Soloveichik, J. Organomet. Chem., 2014, 762, 94-97.

30 J. Yang and M. Brookhart, J. Am. Chem. Soc., 2007, 129, 12656-12657.

31 J. Yang and M. Brookhart, Adv. Synth. Catal., 2009, 351, 175-187.

32 W. E. Geiger and F. Barrière, Acc. Chem. Res., 2010, 43, 1030-1039.

33 R. J. LeSuer, C. Buttolph and W. E. Geiger, Anal. Chem., 2004, 76, 6395-6401.

34 A. P. Abbott and D. J. Schiffrin, J. Chem. Soc., Faraday Trans., 1990, 86, 1453-1459.

35 R. Ghosh, M. Kanzelberger, T. J. Emge, G. S. Hall and A. S. Goldman, Organometallics, 2006, 25, 56685671. 